\title{
RAZONES PARA UNA PERSPECTIVA INTERCULTURAL EN BIOÉTICA
}

\author{
Pamela Chávez Aguilar $1, a$

\section{RESUMEN} \\ La bioética debe tener una perspectiva intercultural. Ello se fundamenta en tres hechos: los principios y valores \\ sobre los que reflexiona pertenecen a cosmovisiones y tradiciones, el ser humano es en sí mismo un ser cultural \\ y las sociedades actuales son enormemente diversas. Para ello, la bioética ha de buscar un adecuado equilibrio \\ entre el universalismo ético y el contextualismo. Esto es un fundamento necesario para el respeto incondicionado \\ a la dignidad humana y para el mutuo reconocimiento, el diálogo, la correlación y la complementariedad entre las \\ diversas culturas.
}

Palabras clave: Bioética; Diversidad cultural; Ética (fuente: DeCS BIREME).

\section{REASONS FOR AN INTERCULTURAL PERSPECTIVE OF BIOETHICS}

\section{ABSTRACT}

Bioethics must have an intercultural perspective. This is based on three facts: The principles and values around which reflection is made are related to world views and traditions, human beings are cultural beings, and current societies are considerably diverse. Based on this, bioethics will seek an adequate balance between ethical universalism and contextualism. This is a fundamental step for unconditional respect for human dignity and mutual recognition, dialogue, correlation and complementarity among diverse cultures.

Key words: Bioethics; Cultural diversity; Ethics (source: MeSH NLM).

\section{PERSPECTIVA INTERCULTURAL DE LA BIOÉTICA}

Se proponen tres consideraciones ante la inquietud de conocer el por qué constituye un imperativo de la bioética pensar su reflexión y quehacer en clave intercultural: 1) pertenece a los fines mismos de la bioética pensar en perspectiva multicultural; 2) existe una base ontológica para ello; 3) es una mirada exigida por el contexto cultural y filosófico actual.

Pertenece a los fines mismos de la bioética. Se puede afirmar que la Bioética es una reflexión interdisciplinaria acerca de los principios y valores involucrados en la acción humana relacionada con la Medicina, las ciencias y las tecnologías que afectan la vida en general, buscando orientar mediante procesos deliberativos la toma de decisiones en situaciones concretas, colaborando paralelamente en la conformación de una ética cívica para sociedades democráticas modernas ${ }^{(1)}$. Esta definición tiene muchos supuestos filosóficos a destacar: su referencia a principios y valores y a una concepción de la vida. Por otra parte, es indudable que nuestras sociedades son multiculturales, puesto que en ellas conviven personas que se sienten pertenecientes a comunidades diversas y cuya identidad, que también es un concepto complejo, puede definirse en base a una etnia, religión, lengua, etc. Supone pues, que una persona puede interpretarse a sí misma como alguien con una identidad específica y sentirse partícipe junto a otros de un grupo o comunidad de sentido, además de pertenecer a una determinada comunidad política. También se hace referencia a la ética cívica, perspectiva que pretende buscar algunos elementos mínimos compartidos que nos permitan convivir juntos, pese a las diferentes tradiciones y sus correspondientes cosmovisiones, planteándose incluso la aspiración de una ética transnacional (2).

Existe una base ontológica. La diversidad es propia de lo humano en cuanto tal, especificidad varón-mujer,

\footnotetext{
Universidad de Chile. Santiago de Chile, Chile.

a Doctora en Filosofía con mención en Ética

Recibido: 19-06-12 Aprobado: 14-11-12
} 
diversidad de etnia, situación geográfica, etc. Por lo tanto, la dimensión multicultural es también antropológica, ontológica; el ser humano es cultural y diverso en sus distintas dimensiones en cuanto individuo o miembro de una comunidad, sociedad o Estado. Como menciona Panikkar: La naturaleza del hombre es cultural (...), un individuo único no es pensable sino como abstracción; (...) el respeto de la dignidad humana exige el respeto cultural ${ }^{(3)}$.

Exigencia por el contexto cultural y filosófico actual. En el contexto de la diversidad cultural de las sociedades modernas, crece la conciencia de la dignidad humana universal más allá de las diferencias y prejuicios, miedo a la cultura diferente, a la pérdida de identidad y valores, estereotipos, estigmatización y la homogeneización cultural como mecanismo de poder y control.

Todo lo anterior se sintetiza en el hecho de que ninguna cultura es, de hecho, universal. Puede existir pretensión de universalidad, como la unificadora razón occidental, pero aún así se ha de reconocer que tal universalidad es en todo caso una aspiración ya que en la realidad se da una diversidad que alcanza al interior mismo de cada cultura. Como fue expresado en el año 2004 por el cardenal Ratzinger en el debate con Habermas: no existe la fórmula universal racional, ética o religiosa en la que todos puedan estar de acuerdo y en la que todo pueda apoyarse ${ }^{(4)}$.

Por último, en la filosofía contemporánea existe cierta desconfianza hacia lo universal. Habermas señala que en la época de la filosofía postmetafísica, esta se abstiene de dar respuestas universales a preguntas como qué sería una vida buena o cuál sería la cultura verdadera, y por tanto se circunscribe a cuestiones normativas en torno a lo justo y sus condiciones formales, es decir, a los procedimientos de construcción de normas morales en sociedades plurales. Este procedimentalismo moral es heredero del formalismo moral kantiano, que sin abandonar la pretensión universalista se opone a las éticas sustantivas que señalarían esto es lo bueno.

En la ética contemporánea también está la discusión entre contextualismo y universalismo, que es un debate que ha decantado también en la confrontación entre liberalismo y comunitarismo; dicho de otro modo, en la pregunta ¿somos ciudadanos de sociedades políticas - Estado - o somos miembros de comunidades? Esa es a primera vista una dicotomía, pero pareciera que pertenecemos a ambos niveles. Entonces, estas dificultades de la ética contemporánea han llevado a ciertas ampliaciones, como una mayor consideración del sujeto ético, de tal manera que se incorporan ahora las diferencias culturales y, en ese sentido, se hacen exigencias como el reconocimiento de todos los individuos y se critica a las corrientes universalistas consideradas como insensibles a las diferencias.

\section{CONTEXTUALISMO, UNIVERSALISMO Y ÉTICA CÍVICA}

Una bioética en clave multicultural no puede olvidar completamente la aspiración a cierta universalidad, porque los rasgos diferenciadores siempre pueden ser también usados como instrumento de discriminación y violencia. Un ejemplo de esos necesarios elementos universales lo constituyen los derechos humanos. En esta tensión universalismo-particularismo es importante pensar en lo que compartimos: un modo de ser como especie humana que supone una dignidad y un modo de ser cultural. Algo de universalismo en ética es siempre necesario, aunque sólo sea la búsqueda de principios racionales que sirvan como un marco referencial irrenunciable de la ética, como la dignidad humana o la no instrumentalización de la persona.

Se trata, entonces, de buscar un equilibrio entre el reconocimiento de las diferencias y el establecimiento de algo común. Charles Taylor señalaba lo siguiente: Debe haber algo a medio camino entre la exigencia, inauténtica y homogeneizadora, de reconocimiento de igual valor, por una parte, y el amurallamiento dentro de las normas etnocéntricas, por la otra. Existen otras culturas y tenemos que convivir, cada vez más tanto en la escala mundial como en cada sociedad individual ${ }^{(5)}$. $Y$ en la búsqueda de dicho equilibrio, es necesario acoger su hipótesis al aproximarnos a cualquier otra cultura: Es razonable suponer que las culturas que han aportado un horizonte de significado para gran cantidad de seres humanos, de diversos caracteres y temperamentos, durante un largo periodo-en otras palabras, que han articulado su sentido del bien, de lo sagrado, de lo admirable- casi ciertamente deben tener algo que merece nuestra admiración y nuestro respeto, aun si este se acompaña de lo mucho que debemos aborrecer y rechazar. Tal vez podamos decirlo de otra manera: se necesitaría una arrogancia suprema para descartar a priori esta posibilidad ${ }^{(5)}$.

De este modo, contextualismo y universalismo son dos herencias que una bioética en clave multicultural ha de incorporar. El universalismo en ética ha estado presente de diversas formas: en la teoría de los derechos humanos o en el formalismo y procedimentalismo moral. La ética cívica, según Adela Cortina, busca asumir un punto de vista moral común para los ciudadanos de las sociedades democráticas modernas, que tienen diversas ideas de bien y felicidad o "éticas de máximos ${ }^{(6)}$. Esta teoría postkantiana, heredera también de la ética discursiva de Habermas y Apel, que busca normas 
racionales con pretensión de universalidad, como racionalidad comunicativa propia de un discurso práctico intersubjetivo, es una "ética de la intersubjetividad", punto de vista moral relevante en orden a situar la ética en nuestro presente.

Pese a que esta propuesta provenga de una visión universalista, desde las distintas culturas podría en cierta medida ser asumido y valorado como tal. Por ejemplo, en la propuesta de valores de la ética cívica, tal como la formula Cortina, encontramos: dignidad humana, que indica que todo ser humano es un valor en sí mismo y tiene dignidad, no debe ser instrumentalizado ni dañado; capacidades, o deber de dar a las personas capacidad para que lleven adelante su vida juntos; justicia, o deber de distribuir los bienes garantizando la igualdad ante la ley y en el acceso a oportunidades, además de la protección especial a los más vulnerables; diálogo, o deber de tomar decisiones teniendo en cuenta los afectados por ellas, principio clave para una política y ética justas; responsabilidad con seres indefensos no humanos o deber de minimizar el daño en seres no humanos y trabajar por un desarrollo sostenible; libertad como autonomía o capacidad de ejecutar o evitar acciones porque percibimos que nos humanizan o deshumanizan; solidaridad o interés mutuo de las personas en una causa común e interés por los asuntos de otros y de la humanidad universal; respeto activo o interés positivo por comprender el proyecto de otro, porque existan condiciones para que lo realice, si es un punto de vista moral respetable, es decir, que se muestre respetuoso de esos valores compartidos.

Por otra parte, estas éticas de tradición universalista como la ética cívica, no se bastan a sí mismas. Tanto Cortina como Habermas han visto que requieren complementaciones; por ejemplo, decimos "es necesario respetar la dignidad humana", pero para asumir esos valores se necesitan algunas condiciones "intrasubjetivas", las cuales ya no fácilmente provienen o son aprendidas desde estas éticas universalistas: sujetos formados en su carácter moral para poder reconocer esos valores y respetarlos, ya que son necesarios para ser ciudadano de sociedades democráticas y para participar en procedimientos dialógicos de establecimiento de normas morales; una auténtica motivación moral que impulse a los sujetos a una actuación en vista del bien común y de esa dignidad; reconocimiento del otro como semejante o "próximo", que está a la base del respeto a la dignidad humana; existencia de un sujeto moral capaz de mirar de frente grandes preguntas, valoraciones, convicciones y compromisos; "buena voluntad", "carácter dialógico" y sentido "compasivo-cordial" sin el cual el sufrimiento humano se hace invisible.
Quizás el principal problema en relación con las culturas, es el reconocimiento del otro y de su diversidad, pues, como ha expresado Cortina, es el reconocimiento recíproco el que nos constituye como personas y nos confiere no un precio, sino la dignidad ${ }^{(2)}$. Rorty ha señalado que el no reconocimiento del otro como "uno de los nuestros" y el sentimiento moral respectivo está a la base de los atropellos a la dignidad humana o a los derechos humanos ${ }^{(7)}$

\section{EN CAMINO HACIA LA INTERCULTURALIDAD}

Según Panikkar, el multiculturalismo nos exige superar algunas actitudes, entre las cuales están el aislamiento y la ignorancia, la indiferencia y el desprecio, la condena y la conquista. Puede ocurrir que en una sociedad coexistan diversas culturas pero ignorándose unas a otras o viéndose mutuamente como una amenaza a suprimir ${ }^{(3)}$. Una vez superado lo anterior, habría que avanzar en dos direcciones que son la coexistencia y la comunicación y, aun más allá, la convergencia y el diálogo. Esto sería avanzar en humanidad y ¿qué es la Bioética sino una búsqueda de humanización de las acciones en el ámbito de la salud y de la vida?

En la discusión actual, encontramos tres conceptos que son dinámicos: multiculturalidad, en referencia al carácter de una realidad donde coexisten diversas culturas; interculturalidad, que parece dar un paso más al hablar de relaciones entre culturas diferentes y apertura al mutuo enriquecimiento, expresando respeto activo y confianza en el valor de las concepciones de otro; y transculturalidad, que alude a una aproximación conjunta a algo común a diversas culturas particulares.

Encontramos elementos interesantes en cada uno de estos conceptos. Es necesario avanzar desde sociedades que no tienen otro camino que asumir su multiculturalidad a sociedades con espacios de interculturalidad, valoración y reconocimiento mutuo. El fundamento de ello sería una experiencia humilde de sí, una percepción de los propios límites, que se relaciona con lo antes dicho: no hay alguna cultura que de hecho sea universal y, por tanto, autosuficiente. Según Panikkar: Ninguna cultura, religión o tradición puede resolver aisladamente los problemas del mundo ${ }^{(3)}$.

La multiculturalidad es también un modo de entender la ciudadanía. Entre los modos del ser ciudadano, Cortina distingue: ciudadanía legal, en cuanto las personas de una comunidad política defienden sus derechos civiles y libertades básicas; ciudadanía política, en cuanto participan en la comunidad política y deliberan sobre 
cuestiones públicas; ciudadanía social, al ser protegidos sus derechos sociales; ciudadanía económica, en cuanto pueden participar del trabajo, tener soberanía como consumidores y autosuficiencia económica. Además de éstas, menciona dos dimensiones especialmente significativas para pensar el tema de la interculturalidad: la ciudadanía compleja, por la cual se reconoce que se es ciudadano desde una diversidad legítima y el reconocimiento de distintas identidades, y la ciudadanía multicultural o intercultural, que reconoce no sólo diferencias culturales sino también la diversidad de cosmovisiones (2).

Una ciudadanía compleja e intercultural tiene desafíos, como la complementación y límites de los derechos individuales y los derechos colectivos; la intolerancia fruto del ver al otro con temor, como una amenaza; cómo "resignificar" los derechos humanos, la democracia y la ética. Esto último es importante, pues si preguntamos a los jóvenes, no necesariamente ellos asumen la democracia o los derechos humanos ni tampoco la ética, porque tienen otras cosmovisiones $u$ otras maneras de vérselas con el mundo ${ }^{(2)}$. Siempre será necesario trabajar por volver a hacer comprensible qué significa respeto al otro.

\section{CONCLUSIONES Y DESAFÍOS}

En el 2004, el filósofo Jürgen Habermas y el cardenal Joseph Ratzinger debatieron sobre si el Estado moderno con democracia liberal necesita o no ser sostenido por las diversas culturas, cosmovisiones y comunidades de sentido. Desde sus distintos puntos de vista, llegaron a un horizonte común: 1) la multiculturalidad es un hecho en las sociedades y Estados modernos; 2) ninguna cultura es de hecho aceptada universalmente, ni siquiera la de la razón científico-técnica occidental; 3) deben reconocerse los aportes que las diversas tradiciones culturales hacen a la conformación de los estados democráticos, como la motivación a la solidaridad o al bien común, la configuración de sentido de la existencia incluso malograda, contenidos de sentido enriquecedores o la posibilidad de mutua autolimitación y vigilancia contra las posibles "patologías" de una cultura, como sería el fundamentalismo o la arrogante autosuficiencia. Todo ello exige una nueva actitud: la disponibilidad a escuchar a otras culturas y a aprender de ellas, el reconocimiento mutuo y el respeto activo; exige admitir la "correlación" entre las culturas, que es una valoración de las identidades diferentes como tales, sin afán de disolverlas, pero abriéndose a la complementariedad ${ }^{(4)}$.

Acoger la realidad multicultural, abrirse positivamente al diálogo intercultural y a la correlación, implica acciones concretas, como propiciar el conocimiento y aprendizaje mutuo; actitudes de respeto y reconocimiento ante el inevitable desacuerdo, propio de lo humano; favorecer que cada cultura pueda dar lo mejor de sí; tomar conciencia de lo que significa el valor de la paz. Como lo señalaba Cortina: Mientras la vida cotidiana no sea en realidad multicultural, seguirá pareciendo que hay un abismo entre las culturas, cuando en realidad existe una gran sintonía entre ellas ${ }^{(2)}$.

Fuentes de financiamiento: autofinanciado.

Conflictos de interés: el autor declara no tener conflictos de interés en la publicación de este artículo.

\section{REFERENCIAS BIBLIOGRÁFICAS}

1. Cortina A. El quehacer público de las éticas aplicadas: ética cívica transnacional. En: Cortina A, GarcíaMarzá D (ed.). Razón pública y éticas aplicadas. Los caminos de la razón práctica en una sociedad pluralista. Madrid: Tecnos; 2003. p. 13-44.

2. Cortina A. Justicia cordial. Madrid: Trotta; 2010.

3. Panikkar R. Paz e interculturalidad. Una reflexión filosófica. Barcelona: Herder; 2006
4. Habermas J, Ratzinger J. Entre razón y religión. Dialéctica de la secularización. México: Fondo de Cultura Económica de España S.L.; 2008.

5. Taylor Ch. El multiculturalismo y "la política del reconocimiento”. México: Fondo de Cultura Económica; 1993.

6. Cortina A. Ética de la razón cordial. Educar en la ciudadanía en el siglo XXI. Oviedo: Nobel; 2007.

7. Rorty R. (1998), Derechos humanos, racionalidad y sentimentalidad. En:
Shute S, Hurley S (ed.). De los derechos humanos. Conferencias Oxford Amnesty de 1993. Madrid: Trotta; 1998. p. 117-36.

Correspondencia: Pamela Chávez Aguilar Dirección: Universidad de Chile. Av. Ignacio Carrera Pinto 1025, piso 3, Nuñoa, Santiago, Chile.

Teléfono: (56-2) 9787026

Correoelectrónico:pchavez@u.uchile.cl 